\title{
Long term effects of maternal nutrition and childhood growth on later health
}

\section{Editorial}

Low birthweight (LBW) has been defined as weight of less than 2500 grams in a given time period by the World Health Organization (WHO). LBW is closely related to fetal and neonatal mortality and morbidity, growth retardation and cognitive developmental disorders, and greater risk of chronic diseases later in life. More than 20million low birth weight infants are born each year in the world, 95.6 percent of them are concentrated in two regions of the developing world: Asia and Africa. Half of all LBW infants are born in South-central Asia. ${ }^{1}$

In 1986, Barker and collegues ${ }^{2,3}$ were the first who published the concept that an adverse intrauterine environment contributed to the onset of the diseases later in life. They reported a correlation between low birth weight and a greater risk of coronary heart disease in later life. Severe inrauterine growth retardation (IUGR) contributes to reduced endocrine pancreatic tissue and dysfunction of $\beta-$ cells $^{4,5}$ which might restrict the function of $\beta$-cells in future and lead to the increased incidence of non-insulin-dependent diabetes mellitus. Furthermore, several studies have been reported the outcomes of IUGR and LBW such as hypertension, ${ }^{6}$ increasing rate of cardiovascular mortality, insulin resistance, impaired glucose tolerance and type 2 diabetes mellitus. ${ }^{7}$ Also, by increasing birth weight, this trend reduced progressively. ${ }^{8}$ Moreover, an association was found between low birth weight and the presence of metabolic syndrome. ${ }^{9}$

It is shown that the higher incidences of disease following a U-shaped curve, including both those born small and those born large. ${ }^{10}$ Several factors involved in the duration of gestation and fetal growth, and thus, the birth weight. These factors are related to the infant, the mother, or the physical environment and have a major role in prediction of the birth weight and the future health of the inewborn. LBW mainly results from poor maternal nutrition before and during pregnancy. Insufficient maternal weight gain is the most important cause of fetal growth retardation. ${ }^{1}$ In addition, a heavy physical activity level during pregnancy may also associated with lower birth weights and pregnancy weight gain. ${ }^{10}$

The term Developmental Origins of Adult Health and Diseases $(\mathrm{DOHaD})$ is focused on the relationship between fetal and postnatal growth, and adult metabolic diseases. ${ }^{11}$ Studies worldwide have shown a consistent association between low birth weight and diabetes type 2 in adult life that has been corrolated to a programmed response to intrauterine malnutrition. ${ }^{12}$ |The etiology of type 2 diabetes is multifactorial, including strong contributions from adult obesity and lifestyle as well as genetic factors and would be prevented by reduction of several critical exposures. Applying the interventions in population to increase birth weight (changing maternal nutrition or smoking habits) could generally increase birth weight especially in populations with marginal nutrition status. Such interventions could reduce the risk of type 2 diabetes $5 \%$ to $10 \% .{ }^{13}$ The fetal insulin hypothesis offers an alternative explanation for the consistent association between impaired fetal growth and insulin resistance during life and the link with hypertension and vascular disease. ${ }^{12}$
Volume 3 Issue 3 - 2015

\author{
Mohammad Reza Vafa,' Salma \\ Mahmoodianfard ${ }^{2}$ \\ 'Department of Nutrition, Iran University of Medical Sciences, \\ Iran \\ ${ }^{2}$ Department of Clinical Nutrition and Tehran University of \\ Medical Sciences, Iran
}

Correspondence: Mohammad Reza Vafa, Department of Nutritional Sciences, School of Public Health Iran University of Medical Sciences, Tel +98 21 86704743, Fax +98 21 88622707, Email rezavafa@yahoo.com

Received: October 17, 2015 | Published: October 27, 2015

The most important mechanisms for explaining the fetal origins of the disease in later life include; hypothalamic pituitary axis alteration, epigenetic regulation of gene expression and oxidative stress which all of these mechanisms may be activated at different stage of gestation and involved in metabolic syndrome development in adult life. ${ }^{11}$

\section{Underlying mechanisms}

The fetal programming hypothesis believes that early events in life contribute to susceptibility to chronic diseases including type 2 diabetes in adult life .Low birth weight results from growth restriction in the uterus which may associate to poorly developed pancreatic $\beta$-cell mass and functionality, retardation in development of skeletal muscle, alteration in set point of the hypothalamic - pituitary -adrenal axis, or epigenetic alterations including methylation of DNA. ${ }^{14}$ All above mentioned changes may subsequently influence on insulin secretion or insulin resistance. These alterations may overlap with genetic trajectory relating to the onset of type 2 diabetes. ${ }^{15}$ Also, presence of the interactions between low birth weight and genetic factors are possible. It has been shown that genetic variants of obesity, which are more linked to insulin resistance, are more regulated by weight at birth than the genetic variants of type 2 diabetes, which are more closely associated to insulin secretion. ${ }^{16}$ Epigenetic modifications may consider as a mechanism by which exposure to an alteration of the intrauterine environment or metabolic disorder may affect the organism phenotype in later life. In the IUGR animal model, it has been clearly considered that epigenetic regulation has a critical role in gene expression of $\beta$-cells and muscles. Theoretically", the animal model of IUGR could explain the crucial appropriate epigenetic mechanisms of gene regulation in the adipocyte and determine specific epigenetic modifications that concern to the manifestation of adiposity and obesity phenotype. ${ }^{17}$

Excessive reactive oxygen species may result in modulation of gene expression and/or detrimental effects on membrane of the cells and other molecules. ${ }^{18}$ Many believe that oxidative stress which accounts as a common factor relating to several disorders, is the primary link between undernutrition and increasing risk of chronic 
diseases in adult life. Known sources of oxidative stress including smoking, gestational hypertension, inflammation, infection, obesity, and malnutrition are associated with low birth weight. ${ }^{19}$ Proteins are needed for antioxidant synthesis, such as glutathione, also some micronutrients such as vitamins $\mathrm{A}, \mathrm{C}$, and $\mathrm{E}$ are antioxidants. ${ }^{20} \mathrm{~A}$ human study ${ }^{21}$ reported significant higher levels of vitamin A, C, and $\mathrm{E}$ in term babies compared to preterm ones. Thus preterm babies were more susceptible to oxidative stress. But only neonatal levels of vitamin $\mathrm{A}$ and $\mathrm{E}$ were dependent on maternal levels. Reactive oxygen species are also detrimental for sensitive pancreatic $\beta$-cells due to low levels of enzymatic antioxidant defense. ${ }^{22}$ Higher susceptibility of pancreatic $\beta$-cells to oxidative stress could contribute to metabolic syndrome and related disorders. ${ }^{19}$ Protein and micronutrient deficiency during the fetal development can result in a pro-oxidant state which relating to elevated risks of the metabolic syndrome..$^{20}$ Elevation in levels of oxidative stress has been observed in infants born small for gestational age as compared to those appropriate for gestational age. ${ }^{23}$

\section{Pre-pregnancy weight, maternal weight gain and obesity in the offspring}

Overweight and obese women are more suceptible to several pregnancy cosequences, including gestational diabetes mellitus, hypertension, preeclampsia, cesarean delivery, and postpartum weight retention. Also, fetuses of these women have higher risk of prematurity, stillbirth, congenital anomalies, macrosomia with possible birth injury, and childhood obesity. Furthermore, obese women have difficulty for initiation and maintenance of breastfeeding.

Obesity in pregnancy is associated to an increased maternal and perinatal morbidity and mortality. ${ }^{24}$ Maternal over nutrition and obesity and gestational diabetes lead to fetal over nutrition and overgrowth. These conditions have deleterious effects on the offspring including obesity, insulin resistance and type 2 diabetes, metabolic syndrome and cardiovascular diseases. ${ }^{25}$

High Birth weight and obesity: Observational studies that found association of higher birth weight with higher achieved BMI, suggested the programing hypothesis of utero determinants of birth weight responsible for elevated risk of obesity later in life. Altered metabolism of maternal glucose and hyperglycemia contribute to excess fetal insulin as a growth hormone for the fetus. ${ }^{26}$ So, gestational diabetes mellitus (GDM) mothers would have off springs with higher birth weights.

Relationship between breastfeeding and obesity in childhood: Breast-feeding has shown protective effects on the risk of obesity in long-term. So, it considers as an important preventive strategy due to considerable public health benefits. ${ }^{27}$ Earlier studies ${ }^{28,29}$ have reported a protective effects of breast-feeding on risk of overweight and lower prevalence of overweight among adolescents, an effect that became more apparent by increasing the duration and exclusive breast-feeding.

Birth weight and Type 2 diabetes: Barker's hypothesis has been noted in associations of many diseases including the relationship between low birth weight and type 2 diabetes in adult life. ${ }^{18}$ In most of the populations examined, birth weight was inversely associated to risk of type 2 diabetes later in life. ${ }^{30}$ These associations were independent of adjusting for adult body size or socioeconomic status. Data has shown that per 1-kg increase in birth weight the reduction of type 2 diabetes risk would be about one-fifth.

Birth weight and hypertention: Alteration in circulating glucocorticoids may contribute to early programming of disease in adulthood. Several studies have suggested that reduced fetal growth leads to a longlasting effects on the set-point of the hypothalamicpituitary-adrenal (HPA) axis. ${ }^{18}$ Exposure to a diversity of stressors such as specific nutrient restriction in pregnant animal models, contribute to an increase in secretion of basal or stress-induced glucocorticoids in the neonates. Thus, exposure to stressors during pregnancy subsequently results in excessive fetal exposure to glucocorticoids leading persistent alterations in the activity of HPA axis. ${ }^{31}$

\section{Maternal malnutrition and risk of diseases}

Maternal Macronutrient deficiency; protein and carbohydrates, leads to lower birth of weight, a marker relating to fetal growth and subsequently insulin resistance, glucose intolerance, hypertension and adiposity in later in life. ${ }^{11}$ Both macro- and micronutrients are critical for appropriate pregnancy outcomes as well as growth of the fetus. While the macronutrients are involved in providing enough energy and proteins for fetal growth, micronutrients are essential for the appropriate macronutrients metabolism, structural and cellular metabolism of the fetus. ${ }^{32}$

Maternal Calorie restriction: Maternal eating disorders increase the risk of having a neonate with LBW. Data from famine studies ${ }^{33}$ carried out during the World War II reported that maternal malnutrition associated with birth outcomes. This calorie restriction led to average $2.5 \mathrm{~kg}$ maternal weight loss compared to pre-famine levels. Maternal weigh loss resulted in major (approximately $300 \mathrm{~g}$ ) reductions in mean birth weight at the height of the famine.

Protein: Studies relating maternal protein restriction and birth outcome are largely based on rodent models. Maternal low protein diet during gestation and lactation was associated to offspring growth retardation. ${ }^{11}$ Low protein diet during gestation and lactation have been shown to result in impaired pancreatic development and reducing $\beta$-cell mass and consequently reduced insulin secretion later in life. ${ }^{34}$

Carbohydrate: Exposure to a sucrose-rich diet $(70 \%$ calories as sucrose) in early stage of life starting $1 \mathrm{wk}$ before breeding, during pregnancy, at birth, and after weaning of the offspring led to longtime postnatal matabolic responses including higher adiposity and a significant increase in triglyceride liver content together with unfavorable alteration in LDL concentrations in offspring.

Fat: High intake of dietary fat, especially of SFA, is associated with an elevation in cardiovascular disease risk. A few animal studies suggested that high consumption of fat during gestation may predispose the appearance of the metabolic syndrome in offspring in adult life.

Maternal micro-nutrient deficiency: Maternal intak of micronutrients are related to fetal exposure to glucocorticoids. The importance of early life stages of the micronutrient deficiency in association with adult diseases have been investigated only in few human studies. ${ }^{18}$ Dietary maternal restriction of copper, zinc, and vitamin $\mathrm{E}$ in a mouse model exhibited a reduction in the activity of placental $11 \beta$-hydroxysteroiddehydrogenase- 2 , an enzyme that contributes to protection of fetus from overexposure to maternal glucocorticoids. ${ }^{35}$ As discussed before, fetal overexposure to glucocorticoids is related to smaller size of newborn, insulin resistance and hypertension later in life. Significant reduction has seen in newborn body weight, increased blood pressure and insulin levels in offspring exposed to the micronutrient restricted diet in comparison to those exposed to a control diet. 
Maternal macronutrient deficiency leads to lower birth of weight and subsequently insulin resistance, glucose intolerance, hypertension and adiposity in later in life. In contrast, consuming diets high in fat and sugar during pregnancy are showed to be related to increasing risk of metabolic syndrom. Evidance of the role of maternal micronutrient deficiencies in programming of chronic diseases in adulthood is less clear. It has been suggested that, micronutrient deficiencies are related to long-term negative effects such as metabolic syndrome and related offspring disorders. For instance, it seems that maternal vitamin A \& D deficiency contribute to hypertention and impaired glucose tolerance in later life. Moreover, deficiencies of calcium or vitamin B12 during pregnancy were related to higher rate of insulin resistance in off springs. Maternal restriction of iron consumption was corrolate to lower birth weight of offspring and growth retadtaion. Future studies are necessary in order to determine the exact role of maternal micronutrient deficiencies on early programming of chronic diseases. Understanding their precise patho-physiological mechanism are critical to establish new procedures to prevent the adverse effects of maternal dietary restriction and environmental factors in early stages of life.

\section{Acknowledgements}

None.

\section{Conflict of interest}

The author declares no conflict of interest.

\section{References}

1. United Nations Children's Fund and World Health Organization. Low Birthweight: Country, regional land global estimates. USA:UNICEF; 2004.

2. Barker DJ, Osmond C. Low birth weight and hypertension. BMJ. 1988;297(6641):134-135.

3. Barker DJ, Osmond C, Winter PD, et al. Weight in infancy and death from ischaemic heart disease. The Lancet. 1989;2(8663):577-580.

4. Van Assche FA, De Prins F, Aerts L, et al. The endocrine pancreas in small-for- dates infants. Br J Obstet Gynaecol. 1977;84(10):751-753.

5. Nicolini U, Hubinont C, Sant olaya J, et al. Effects of fetal intravenous glucose challenge in normal and growth retarded fetuses. Horm Metab Res. 1990;22(8):426-430.

6. Barker DJ. In utero programming of chronic disease. Clin Sci. 1998;95(2):115-128.

7. Jaquet D, Gaboriau A, Czernichow $\mathrm{P}$, et al. Insulin resistance early in adulthood in subjects born with intrauterine growth retardation. J Clin Endocrinol Meta. 2000; 85(4):1401-1406.

8. Hales CN, Barker DJ, Clark PM, et al. Fetal and infant growth and impaired glucose tolerance at age 64. BMJ. 1991;303(6809):1019-1022.

9. Barker DJ, Hales CN, Fall C, et al. Type 2 (non-insulin-dependent) diabetes mellitus, hypertension and hyperlipidaemia (syndrome $\mathrm{X}$ ): relation to reduced fetal growth. Diabetologia. 1993;36(1):62-67.

10. Muthayya S. Maternal nutrition \& low birth weight-what is really important? Indian J Med Res. 2009;130(5):600-608.

11. Lakshmy R. Metabolic syndrome: role of maternal undernutrition and fetal programming. Rev Endocr Metab Disord. 2013;14(3):229-240.

12. Hattersley AT, Tooke JE. The fetal insulin hypothesis: an alternative explanation of the association of low birth weight with diabetes and vascular disease. Lancet. 1999;353(9166):1789-1792.
13. Whincup PH, Kaye SJ, Owen CG, et al. Birth weight and risk of type 2 diabetes: a systematic review. JAMA. 2008;300(24):2886-2897.

14. Li Y, Qi Q, Workalemahu T, et al. Birth weight, genetic susceptibility, and adulthood risk of type 2 diabetes. Diabetes care. 2012;35(12):24792484 .

15. Gluckman PD, Hanson MA, Cooper C, et al. Effect of in utero and early- life conditions ion adult health and disease. $N$ Engl J Med. 2008;359(1):61-73.

16. McCarthy MI. Genomics type 2 diabetes, and obesity. $N$ Engl J Med. 2010;363(24):2339-2350.

17. Pinney SE, Simmons RA. Epigenetic Changes Associated with Intrauterine Growth Retardation and Adipogenesis. In: Lustig RH, editor. Obesity Before Birth. USA: University of California, Springer; 2010. p. $167-189$.

18. Brenseke B, Prater MR, Bahamonde J, et al. Current thoughts on maternal nutrition and fetal programming of the metabolic syndrome. Journal of pregnancy. 2013:2013:1-13.

19. Luo ZC, Fraser WD, Julien P, et al. Tracing the origins of fetal origins of adult diseases: programming by oxidative stress. Med Hypotheses. 2006;66(1):18-44.

20. Willcox JK, Ash SL, Catignani GL. Antioxidants and prevention of chronic disease. Crit Rev Food Sci Nutr. 2004;44(4):275-295.

21. Baydas G, Karatas F, Gursu MF, et al. Antioxidant vitamin levels in term and preterm infants and their relation to maternal vitamin status. Arch Med Res. 2002;33(3):276-280.

22. Lenzen S. Oxidative stress: the vulnerable $\beta$-cell. Biochem Soc Trans. 2008;36(3):343-347.

23. Goldsmith L, Katz S, Gilchrest B, et al. Micronutrients. Fitzpatrick'S Dermatology in General Medicine. 7th ed. USA: McGraw-Hill; 2008. p. $1264-1264$.

24. American College of Obstetricians and Gynecologists. ACOG Committee Opinion No. 549: Obesity in Pregnancy. Obstet Gynecol. 2013;121(1):213-217.

25. Van Assche FA. Diabetes and pregnancy. In: Carrera J, editor. Recommendations and Guidelines for Perinatal Medicine. Spain: On initiative of World Association Of Perinatal Medicine (WAPM) and Matres Mundi International. Matres Mundi International, EGS; 2007. p. 97-103.

26. Gillman MW, Rifas-Shiman S, Berkey CS, et al. Maternal gestational diabetes, birth weight, and adolescent obesity. Pediatrics. 2003;111(3):e221-e226.

27. Crume T, Dabelea D. Exposure to Diabetes In Utero, Offspring Growth, and Risk for Obesity. In: Lustig RH, editor. Obesity Before Birth. USA: University of California, Springer; 2011. p. 193-204.

28. Gillman MW, Rifas-Shiman SL, Camargo CA, et al. Risk of overweight among adolescents who were breastfed as infants. JAMA. 2001;258(19):2461-2467.

29. Mayer-Davis EJ, Rifas-Shiman SL, Zhou L, et al. Breast-feeding and risk for childhood obesity: does maternal diabetes or obesity status matter? Diabetes Care. 2006;29(10):2231-2237.

30. Harder T, Rodekamp E, Schellong K, et al. Birth weight and subsequent risk of type 2 diabetes: a meta-analysis. Am J Epidemiol. 2007;165(8):849-857.

31. Phillips DI. Fetal growth and programming of the hypothalamicpituitary-adrenal axis. Clin Exp Pharmacol Physiol. 2001;28(11):967970 .

32. Rao KR, Padmavathi IJN, Raghunath M. Maternal micronutrient restriction programs the body aldiposity, adipocyte function and lipid metabolism in offspring: A review. Rev Endocr Metab Disord?. 2012;13(2):103-108. 
33. Imdad A, Bhutta ZA. Maternal Nutrition and Birth Outcomes: Effect of Balanced Protein-Energy Supplementation. Paediatr Perinat Epidemiol. 2012;26(suppl1):178-190.

34. Petrik J, Reusens B, Aranyetal E, et al. A low protein diet alters the balance of islet cell replication and apoptosis in the fetal and neonatal rat and is associated with a reduced pancreatic expression of insulin-like growth factor-II. Endocrinology. 1999;140(10):4861-4873.
35. Rosario JF, Gomez MP, Anbu P. Does the maternal micronutrient deiciency (copper or zinc or pitamin E )modulate the expression of placental $11 \beta$ hydroxysteroid dehydrogenase-2 per se predispose of spring to insulin resistance and hypertension in later life? Indian $J$ Physiol Pharmacol. 2008;52(4):355-365. 